\title{
Choice of Prizes Allocated by Multiple Lotteries with Endogenously Determined Probabilities
}

\author{
Amnon Rapoport \\ Alison King Chung Lo \\ University of Arizona \\ Duke University \\ Rami Zwick \\ Hong Kong University of \\ Science and Technology
}

March 6, 2001

Please address all correspondence to:

Amnon Rapoport

Department of Management and Policy

Eller School of Business

405 McClelland Hall

University of Arizona

Tucson, AZ 85721

E-mail address: amnon@u.arizona.edu

\section{Acknowledgement}

We acknowledge support of this research by a grant from the Hong Kong Research Grants Council (Project No. CA98/99.BM01). The first author wishes to thank the Marketing Department at the Hong Kong University of Science and Technology for its support and hospitality. 


\begin{abstract}
We study a class of interactive decision making situations in which each agent must choose to participate in one of several lotteries with commonly known prizes. In contrast to the widely studied paradigm of choice between gambles in individual decision making under risk in which the probabilities of the prizes are given, the probability of winning a prize in each of the lotteries in our study is known to decrease in the number of agents choosing this lottery. We construct the Nash equilibrium solution to this game and then test it experimentally in the special case where each lottery yields only a single prize. The results show a remarkable degree of tacit coordination that supports the equilibrium solution under the assumption of common risk-aversion. However, this coordination is not achieved via individual level randomization. Rather, the entry decisions of most of the subjects can be characterized by local adjustments to the outcome of the previous iteration of the same game along the lines suggested by anticipatory learning models.
\end{abstract}




\section{Introduction}

It often happens in markets that the demand for some good far exceeds the supply, but suppliers do not increase prices in order to reduce demand. This is the case when there is a surge in demand for new products (e.g., toys, electronic gadgets) that are introduced in the market at a fixed price and become fashionable, or when tickets for popular concerts and other cultural events are sold to the general public. In general, shops do not increase the price of air conditioners when there is a surge in demand due to a heat wave, customers are not required to pay more for snow shovels after a severe snow storm, and restaurants do not increase their prices on Saturday nights (Kahneman, Knetsch, \& Thaler, 1986) ${ }^{1}$. Depending on the nature of the good and the social context, societies have developed alternative mechanisms to allocate the limited supply.

\section{Mechanisms for allocating limited supply}

A common mechanism is the priority list in which claimants are ranked according to some measure of need, contribution, seniority, power, or some combination of factors. For example, priority to receive an organ for transplantation may depend on the likelihood of success of the transplantation, urgency of the case, and other related factors; and admission to public housing often depends on financial need and family size (Young, 1994). The problem with this mechanism is that the criteria for determining priority lists are often open to heated debate raising controversial issues of fairness. A second mechanism for allocating indivisible goods that are in short supply is simply to distribute them to those who demand them first. Seats in popular restaurants, tickets for most sport events, and new products (e.g., Sony Play Station 2) are typically sold in this fashion. The problem with this popular "first come, first served" mechanism is that it creates inefficiencies (queueing in lines), imposes hardship on the claimants, and penalizes customers who cannot stand in line. For example, McDonald's has recently been criticized by a political party in Hong Kong over the long queues formed by 
consumers to collect the "Hello Kitty" and "Dear Daniel" toys that it distributed in its restaurants. A Democratic Party legislator suggested that "McDonald's should consider lucky draws" (Hong Kong Standard, July 20, 1999). This takes us to a third mechanism that avoids the inefficiencies associated with the "first come, first served" mechanism and the controversies associated with allocation by priority lists. This mechanism distributes the limited supply by a lottery. For example, apartments in new development housing projects in Hong Kong, positions in medical schools in the Netherlands (Young, 1994), hunting permits, and IPO shares to individual investors are allocated in this manner. The principle underlying this mechanism is of no preferential treatment; each of the claimants is assigned the same probability of getting it ${ }^{2}$.

The major feature of these lotteries is that the probability of winning a given prize is determined endogenously so that the larger the number of persons participating in the lottery, the smaller the probability of winning one of the prizes it offers. Our interest in the present paper is in problems of tacit coordination that arise when claimants can register to only one of several independent lotteries. For example, households in Hong Kong seeking to purchase a new apartment (a commodity in short supply) are often presented with alternative public development projects that put out for sale (at a fixed and attractive price) individual apartments by lottery, but are prohibited by law from registering for more than a single apartment (to prevent speculation).

The lottery mechanism is not to be interpreted narrowly; it has other interpretations that dispense with the need of throwing dice, tossing coins, or using some other random device to determine the allocation of prizes. For example, consider the case of homogenous firms, each faced with the decision which of several newly emerging markets to enter. The larger the number of entrants into the market, the smaller the entrant's profit. The firms may fully recognize their mutual interdependence. Budget constraints often prohibit them from entering 
more than a single market. Although no physical lotteries are involved in this case, each firm's decision is typically based on the conditional probability of successful entry into one of the markets, given the anticipated number of entrants into this market (as well as on the profit associated with successful entry into one of the different markets). If the subjective probability of each firm of successful entry into a given market is proportional to the number of entrants into the same market (in other words, each firm believes that its chances of success are neither better nor worse than those of any other of the competing firms), these commonly shared beliefs operate like a lottery mechanism.

Whether a lottery mechanism is physically used to allocate the prizes or the system of commonly shared beliefs operates like a lottery mechanism, the decision is strategic because the probability of winning any given prize, once one of several alternatives (e.g., housing projects, newly emerging markets) is chosen, depends not only on the number and values of the prizes associated with each of the alternatives, but also on the decisions made by other participants. Depending on the assumptions made about the agent's information structure, interactive decision making situations of this type may be modeled as non-cooperative nperson games under either complete or incomplete information. However modeled, these situations include two sources of uncertainty: strategic uncertainty about the choices made the by the other agents, and outcome uncertainty about the result of the lottery chosen to be played by the agent.

The purpose of the present research is to investigate tacit coordination under both sources of uncertainty when $n$ agents have to choose only one of several alternatives (lotteries) in which the prizes associated with the choice of each alternative are determined probabilistically. Because there is no simple way to assess systems of beliefs and verify whether or not they are commonly shared in real-life situations, we resort to experimentation 
that uses physical lotteries. We propose a game to simulate the situation, construct its Nash equilibrium solution, and then examine its descriptive power.

The paper is organized as follows. Section 2 describes the Consumer Choice of Prizes (CCP) game that we propose for simulating basic features of the problem, and then constructs and illustrates its multiple equilibria. Section 3 describes a laboratory experiment that allows for only a single prize in each location but varies the values of the different prizes. The CCP game is extended in Section 4 to the case where only the distribution of the group size $n$, rather than the exact value of $\mathrm{n}$, is commonly known. Section 5 discusses the results.

\section{Theory}

\section{The CCP Game}

The CCP game is a non-cooperative n-person game with complete information. The game is played by a group of $\mathrm{n}$ subjects. There are $\mathrm{J}$ separate alternatives (called locations) with $\mathrm{m}_{\mathrm{j}}$ identical prizes in each location $\mathrm{j}(\mathrm{j}=1,2, \ldots, \mathrm{J})$. Each prize is worth $\mathrm{g}_{\mathrm{j}}$ units.

Once publicly informed of the values of $n, J, m_{j}$, and $g_{j}$, each subject $i$ must decide independently and anonymously which location to enter. Denote the number of entrants in location $\mathrm{j}$ by $\mathrm{n}_{\mathrm{j}}\left(\sum_{j=1}^{J} n_{j}=\mathrm{n}\right)$. Once all the $\mathrm{n}$ subjects make their entry decisions, individual payoffs are determined for each subject as follows:

If $n_{j} \leq m_{j}$, then each entrant in location $j$ receives the prize $g_{j}$.

If $n_{j}>m_{j}$, then the $m_{j}$ prizes are distributed by lottery among the $n_{j}$ entrants such that exactly $m_{j}$ subjects receive one prize each.

\section{$\underline{\text { Equilibrium Solutions }}$}

Because the players are symmetric, we focus only on the symmetric mixed strategy equilibrium in which each of the $\mathrm{n}$ players enters locations $1,2, \ldots, \mathrm{J}$ with respective probabilities $\mathrm{q}_{1}, \mathrm{q}_{2}, \ldots, \mathrm{q}_{\mathrm{J}}$. Without loss of generality, assume that the $\mathrm{J}$ locations are ordered 
from 1 through $J$ in terms of $m_{j} q_{j}$. To ensure that each location is chosen with some probability, small as it may be, we require that $\mathrm{n}>\mathrm{g}_{1} \mathrm{~m}_{1} / \mathrm{g}_{\mathrm{j}} \mathrm{m}_{\mathrm{j}} \forall \mathrm{j}$. Recall that the $\mathrm{J}$ locations are independent, and that if entering location $\mathrm{j}$, player $\mathrm{i}$ either receives the prize $\mathrm{g}_{\mathrm{j}}$ with certainty (if $n_{j} \leq m_{j}$ ) or with probability $m_{j} / n_{j}\left(\right.$ if $\left.n_{j}>m_{j}\right)$. Therefore, the equilibrium solution for risk-neutral players consists of the probability values $q_{1}, q_{2}, \ldots, q_{J}$, that satisfy the following $J+1$ equations in $J+1$ unknowns $\left(q_{1}, q_{2}, \ldots, q_{J}, V\right)$ :

$$
\mathrm{g}_{\mathrm{j}} \sum_{k=0}^{m_{j}-1}\left(\begin{array}{c}
n-1 \\
k
\end{array}\right) \mathrm{q}_{\mathrm{j}}{ }^{\mathrm{k}}\left(1-\mathrm{q}_{\mathrm{j}}\right)^{\mathrm{n}-1-\mathrm{k}}+\mathrm{g}_{\mathrm{j}} \sum_{k=m_{j}}^{n-1}\left(\begin{array}{c}
n-1 \\
k
\end{array}\right)\left(\frac{m_{j}}{k+1}\right) \mathrm{q}_{\mathrm{j}}{ }^{\mathrm{k}}\left(1-\mathrm{q}_{\mathrm{j}}\right)^{\mathrm{n}-1-\mathrm{k}}=\mathrm{V},
$$

and

$$
\sum_{j=1}^{J} q_{j}=1, \mathrm{q}_{\mathrm{j}} \geq 0, \quad \mathrm{j}=1,2, \ldots, \mathrm{J}
$$

where $\mathrm{V}$ denotes the expected value associated with equilibrium play.

In the special case considered in the present study, where each location offers only a single prize $\left(\mathrm{m}_{\mathrm{j}}=1 \forall \mathrm{j}\right)$, the left-hand side of equation (1) simplifies to

$$
\begin{aligned}
& \mathrm{g}_{\mathrm{j}} \sum_{k=0}^{0}\left(\begin{array}{c}
n-1 \\
0
\end{array}\right) \mathrm{q}_{\mathrm{j}}{ }^{0}\left(1-\mathrm{q}_{\mathrm{j}}\right)^{\mathrm{n}-1}+\mathrm{g}_{\mathrm{j}} \sum_{k=1}^{n-1}\left(\begin{array}{c}
n-1 \\
k
\end{array}\right)\left(\frac{1}{k+1}\right) \mathrm{q}_{\mathrm{j}}^{\mathrm{k}}\left(1-\mathrm{q}_{\mathrm{j}}\right)^{\mathrm{n}-1-\mathrm{k}} \\
& =\mathrm{g}_{\mathrm{j}} \sum_{k=0}^{n-1}\left(\begin{array}{c}
n-1 \\
k
\end{array}\right)\left(\frac{1}{k+1}\right) \mathrm{q}_{\mathrm{j}}{ }^{\mathrm{k}}\left(1-\mathrm{q}_{\mathrm{j}}\right)^{\mathrm{n}-1-\mathrm{k}}, \quad \text { for } \mathrm{j}=1,2, \ldots, \mathrm{J} .
\end{aligned}
$$

Omitting the subscript on q, we can write

$$
\begin{aligned}
& \sum_{k=0}^{n-1}\left(\begin{array}{c}
n-1 \\
k
\end{array}\right)\left(\frac{1}{k+1}\right) \mathrm{q}^{\mathrm{k}}(1-\mathrm{q})^{\mathrm{n}-1-\mathrm{k}} \\
& =(1-\mathrm{q})^{\mathrm{n}-1} \sum_{k=0}^{n-1}\left(\begin{array}{c}
n-1 \\
k
\end{array}\right)\left(\frac{1}{k+1}\right)\left(\frac{q}{1-q}\right)^{\mathrm{k}} \\
& =(1-\mathrm{q})^{\mathrm{n}-1}\left(\frac{1-q}{q}\right) \sum_{k=0}^{n-1}\left(\begin{array}{c}
n-1 \\
k
\end{array}\right)\left(\frac{1}{k+1}\right)\left(\frac{q}{1-q}\right)^{\mathrm{k}+1} \\
& =\frac{(1-q)^{n}}{q}\left[\frac{1}{n}\left(\frac{1}{1-q}\right)^{\mathrm{n}}-\frac{1}{n}\right]
\end{aligned}
$$




$$
=\frac{1}{n q}\left[1-(1-\mathrm{q})^{\mathrm{n}}\right]
$$

Thus, if $\mathrm{m}_{\mathrm{j}}=1 \forall \mathrm{j}$, the system of $\mathrm{J}+1$ equations (Eq. 1) simplifies to

$$
\frac{g_{j}}{n q_{j}}\left[1-\left(1-\mathrm{q}_{\mathrm{j}}\right)^{\mathrm{n}}\right]=\mathrm{V}
$$

and

$$
\sum_{j=1}^{J} q_{j}=1, \quad \mathrm{q}_{\mathrm{j}} \geq 0, \quad \mathrm{j}=1,2, \ldots, \mathrm{J} .
$$

These equations are solved numerically.

Pure strategy equilibria consist of $\mathrm{n}_{1}{ }^{*}, \mathrm{n}_{2}{ }^{*}, \ldots, \mathrm{n}_{\mathrm{J}}{ }^{*}$ entrants into locations $1,2, \ldots, \mathrm{J}$, respectively $\left(\sum_{j=1}^{J} \mathrm{n}_{\mathrm{j}}{ }^{*}=\mathrm{n}\right)$, such that no single player benefits from unilaterally switching from location $\mathrm{j}$ to location $\mathrm{j}(\mathrm{j} \neq \mathrm{j})$. Given the parameter values $m_{j}$ and $g_{j}$, the values of $n_{j}{ }^{*}$ are determined computationally. Whereas the symmetric mixed strategy equilibrium is unique, there are multiple pure strategy equilibria. In particular, the number of pure strategy equilibria is given by $n ! /\left(n_{1}{ }^{*} ! n_{2}{ }^{*} ! \ldots n_{J}{ }^{*} !\right)$. Note that with sufficiently many iterations of the same game, the mixed strategy equilibrium solution is testable on both the individual and aggregate levels. In contrast, the pure strategy equilibria are only testable on the aggregate level, as they have no implications for individual play. The number of entrants under pure strategy equilibrium play $\left(\mathrm{n}_{\mathrm{j}}{ }^{*}\right)$ and the expected number of entrants under mixed strategy equilibrium play $\left(\mathrm{nq}_{\mathrm{j}}\right)$ are approximately the same; therefore, obviating the need to test these solutions separately on the aggregate level: $n_{j}{ }^{*} \approx n q_{j}$ for $j=1,2, \ldots, J$.

Table 1 presents the six different games used in our experiment with their parameter values as well as their pure and mixed strategy equilibria. For all six games, $n=18$. The approximation $\mathrm{n}_{\mathrm{j}}{ }^{*} \approx \mathrm{nq}_{\mathrm{j}}$ gets worse as the differences among the prize values increase. For example, the parameter values for Game 1 are $\mathrm{g}=\left(\mathrm{g}_{1}, \mathrm{~g}_{2}, \mathrm{~g}_{3}\right)=(14,12,10)$ and $\underline{\mathrm{m}}=\left(\mathrm{m}_{1}, \mathrm{~m}_{2}\right.$, 
$\left.\mathrm{m}_{3}\right)=(1,1,1)$. Under mixed strategy equilibrium play the respective probabilities of entry are $0.389,0.334$, and 0.277 , and the associated expected number of entrants $\left(\mathrm{nq}_{\mathrm{j}}\right)$ are 7.002 , 6.012 , and 4.986 . These values come very close to the number of entrants under pure strategy equilibrium play, namely, 7, 6, and 5. The largest discrepancy occurs in Game 6 where the expected frequencies of entry in locations 1,2 , and 3 under mixed strategy equilibrium play are $16.308,1.818$, and 0.144 , respectively, compared with the pure strategy equilibrium number of entrants, namely, 15, 2, and 1 . It is easy to verify that for any distribution of the prize values, the approximation improves as $n$ increases: $\mathrm{nq}_{\mathrm{j}} \rightarrow \mathrm{n}_{\mathrm{j}}{ }^{*}$ as $\mathrm{n} \rightarrow \infty$.

--Insert Table 1 about here--

\section{Experiment}

\section{$\underline{\text { Method }}$}

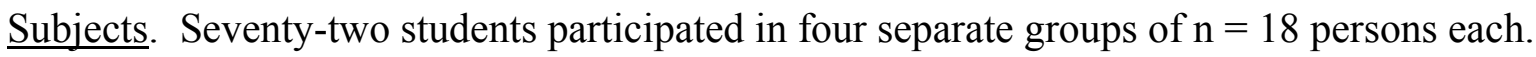
The participants were Hong Kong University of Science and Technology students, mostly undergraduate students of business administration, who volunteered to take part in a single session of a decision making experiment for payoff contingent on performance. Participants earned on the average HK\$145.92 plus HK\$30.00 show-up fee for an average total payoff of HK\$175.92 per participant ${ }^{3}$ (approximately US\$22.8). The payoff ranges were [76, 204], [76, 222], [52, 304], and [88, 226] for Groups 1, 2, 3, and 4, respectively.

Experimental Design. The experimental design consisted of six different games $(\mathrm{G}=1,2, \ldots$ ., 6 ) each of which iterated 12 times (blocks) for a total of $6 \times 12=72$ trials. Only a single prize was offered by each of the three lotteries in each of the six games $\left(\mathrm{m}_{1}=\mathrm{m}_{2}=\mathrm{m}_{3}=1\right)$, whereas the prize values differed across the six games (Table 1). The six games were constructed to differ from one another in the variability of the prizes. We measured this variability by the range of the three prizes, denoted by $\Delta$ (Table 1$)$. The ranges for games 1,2 , 
$3,4,5$, and 6 were $4,10,10,18,20$, and 28 , respectively. The sum of the prizes was fixed at \$36 for each game $\mathrm{G}$.

Procedure. The experiment was computer-controlled. Upon arrival at the computer laboratory (which contains 80 PCs), the members of each group were seated at one of 18 computer terminals that were spread over the entire laboratory. Communication between the participants was prohibited. The instructions were presented on the individual computer screens in front of the participants using PowerPoint Slide Show ${ }^{4}$. The participants read the instructions at their own pace with no time pressure. The first twelve computer screens of the instructions are reproduced in the Appendix 5 .

The participants were instructed that they would take part in a game played repeatedly. Their task was to choose one of three lotteries, called (and marked on the screen) Yellow, Blue, and Red. At the beginning of the round, the prize values $\left(\mathrm{g}_{\mathrm{j}}\right)$ and number of prizes in each lottery $\left(\mathrm{m}_{\mathrm{j}}\right)$ were displayed to the participants, who were then required to choose one of the three lotteries. Screen 4 of the Appendix shows an example with three lotteries, where $g=(10,15,20)$ and $\underline{m}=(1,1,1)$. (The colors of the three lotteries in the Appendix are suppressed.) The participants were instructed that the game parameters would vary from round to round. Once all of them made their decision, the values of $n_{j}$ were displayed on the individual screens (see screen 6 of the Appendix), and the prizes were distributed (see screens $7-10$ of the Appendix).

After reading the information displayed on the first 12 screens, the participants' understanding of the procedure was tested through four hypothetical questions (not displayed in the Appendix) that varied the parameter values and number of entrants. The experiment commenced only after each of the 18 group members answered these questions correctly. The participants were told that they would be paid their cumulative earnings at the end of the experiment plus HK\$30.00 show-up fee. 
On each of the 12 blocks of trials, Games 1 through 6 (Table 1) were presented in a different random order. To prevent response biases (e.g., color preference), the prize values for the same game were varied across colors in a balanced design, so that each of the six permutations of the three prize values appeared exactly twice. The entire experiment lasted about 75 minutes.

Results

We begin this section with a brief summary of the major findings. We first provide evidence for significant game effects but no differences between the four groups and no evidence for changes in the aggregate choice of entry locations across iterations of each of the six games. Next, we show that the mixed strategy equilibrium solution for risk-neutral players organizes the aggregate results quite well. However, we observe a systematic departure from equilibrium play, namely, an inverted S-shaped function that is first concave and then convex, slightly over-weighting low equilibrium probabilities of entry and underweighting high equilibrium probabilities. This systematic deviation disappears when the assumption of common risk-neutrality is replaced by the assumption of common riskaversion. However, the mixed strategy equilibrium solution does not account for the behavior of most individual players. Rather, most players tend to change their location entry choices less frequently than predicted, and adjust their decisions from one iteration of a game to another along the lines suggested by anticipatory learning models. Evidence in support of these claims is presented below.

\section{Aggregate Decisions.}

The expected payoff per subject under pure strategy equilibrium play is $\$ 2.00$ per trial for a total of $\$ 144.00$ for the entire experimental session. The expected value and standard deviation of the individual payoff for the entire session under mixed strategy equilibrium play are 140.46 and 47.04, respectively. The mean individual payoff of Groups 1, 2, 3, and 4 was 
$146.00,145.78,146.00$, and 145.92, respectively. Although in each group the players earned on the average about 4 percent more that expected, none of the four differences is statistically significant $\left(\mathrm{t}_{18}<1\right)$. Nor is there any evidence for differences between groups with respect to the mean individual payoff.

On the individual level, we find no evidence that some participants earned significantly more money than others. The $95 \%$ significance interval under the mixed strategy equilibrium is $140.46 \pm 77.15$. We find only four participants $(5.56 \%)$ - one in Group 2, two in Group 3, and one in Group 4-outside this confidence interval. Using a chisquare test, we cannot reject the null hypothesis that the distribution of payoffs across the four groups is distributed normally $\left(\chi^{2}(7)=4.90, \mathrm{p}<0.05\right)$.

To further test for differences between groups and trends across time, we divided the 72 rounds of play into six blocks of 12 rounds each. For each round $t(t=1,2, \ldots, 72)$, we computed a root mean square deviation score, $\mathrm{RMSD}_{\mathrm{t}}$, between the observed and predicted number of entries:

$$
\operatorname{RMSD}_{\mathrm{t}}=\frac{1}{J} \sqrt{\sum_{j=1}^{J}\left(n_{j t}-n q_{j t}\right)^{2}},
$$

where $\mathrm{n}_{\mathrm{jt}}$ is the observed number of entries in location $\mathrm{j}$ on round $\mathrm{t}, \mathrm{nq}_{\mathrm{jt}}$ is the expected number of entries in location $\mathrm{j}$ on round $\mathrm{t}$ under mixed strategy equilibrium play, and $\mathrm{J}=3$. These $\mathrm{RMSD}_{\mathrm{t}}$ scores (72 for each group) were then subjected to a $4 \times 6$ group by block ANOVA with repeated measures on the block factor. Neither of the two main effects due to group and block, nor the group by block two-way interaction effect were significant $\left(\mathrm{F}_{3,264}<\right.$ $1, \mathrm{~F}_{5,264}<1$, and $\mathrm{F}_{15,264}<1$, respectively).

To examine the changes across rounds of play more closely, we computed the running mean of the RMSD ${ }_{t}$ scores in steps of 12 (rounds $1-12,2-13, \ldots, 61-72$ ). Figure 1 displays the running means for each group separately and across the four groups (bottom 
panel). There is no indication for changes in the deviation scores across rounds of play for each of the four groups, nor is there any evidence for differences among the four groups. The running means for individual groups vary between 1.1 and 1.8 and do not exhibit any discernible trend. When the data are combined across the four groups, the running means exhibit more stability (bottom panel) due to averaging with only minor oscillations between 1.3 and 1.5. Taken together, these analyses support our claims of no group or learning effects. --Insert Fig. 1 about here--

To test for game effects, the $72 \times 4=288 \mathrm{RMSD}_{\mathrm{t}}$ scores were subjected to a $4 \times 6$ group by game ANOVA with repeated measures on the game factor. As expected from the previous analysis, the main effect due to group was not significant $\left(\mathrm{F}_{3,264}<1\right)$. The group by game interaction effect was also not significant $\left(\mathrm{F}_{15,264}<1\right)$. However, the main effect due to game was highly significant $\left(\mathrm{F}_{5,264}=4.73, \mathrm{p}<0.001\right)$. A post-hoc comparison showed that the game main effect was due to the difference between Games 1 and 3 on the one hand and Games 5 and 6 on the other hand. The mean RMSD scores for Games 1, 2, 3, 4, 5, and 6 were $1.06,1.25,1.13,1.24,1.43$, and 1.52 , respectively. With one exception, these scores increase in the range $(\Delta)$ of the payoffs. The subjects' behavior is better accounted for by the mixed strategy equilibrium solution as the three prizes are closer to one another (and, consequently, the equilibrium probabilities are closer to 0.333 ).

With no evidence for group differences or changes in aggregate choice of entry locations over time, the results were combined across groups and rounds of play. Table 2 (first row in each of the six panels) shows the means and standard deviations (SD) of the observed frequency of location entries. The results are presented separately for each game (across the 12 replications). Table 2 also presents (second row of each panel) the expected values and standard deviations of frequency of entry under mixed strategy equilibrium play 
for risk-neutral players. (The number of entries for each game under pure strategy equilibrium play can be read directly from Table 1.)

--Insert Table 2 about here--

Our major dependent variable is the mean frequency of entry location. Because the group rather than the individual member is the unit of analysis, we present the results separately for each group. Figure 2 portrays the observed relative frequencies of entry against the mixed strategy equilibrium probabilities of entry. The results are displayed separately by group, and then combined across groups in the bottom panel. Figure 2 shows that in each case the observed relative frequencies of entry decisions increase monotonically in the theoretical probabilities. This finding provides strong evidence for tacit coordination. However, there is a systematic deviation from equilibrium play with subjects entering too frequently when the theoretical probabilities are relatively small and too infrequently when they are relatively high. The empirical function in each of the four panels in Fig. 2 crosses the 45 degree diagonal line at a point between 0.3 and 0.4. The results displayed in Fig. 2 are consistent with the shape of the probability weighting function postulated by Prospect Theory for individual decision making under risk (Prelec, 1998; Tversky \& Wakker, 1995) and with the supportive empirical evidence presented by Lattimore et al. (1992) and Wu and Gonzalez (1996, 1998).

--Insert Fig. 2 about here--

\section{$\underline{\text { Value and Probability Weighting Transformations }}$}

The systematic deviation between the observed and predicted frequencies of location entry may be due to the failure of the expected utility hypothesis, which is invoked by the equilibrium solution. We pursue below two alternative explanations for this systematic deviation, which are based on the value and probability weighting transformations proposed by Prospect theory. It may be recalled that Cumulative Prospect Theory (Tversky \& 
Kahneman, 1992), as well as other related non-linear expected utility models, proposes to account for the failure of the expected utility hypothesis by representing individual preferences by a sign and rank dependent functional $\mathrm{V}(\mathrm{P})$, with a value function $\mathrm{v}(\mathrm{x})$ for monetary outcomes, and two probability weighting functions, $\mathrm{w}^{+}(\mathrm{p})$ for gains $(\mathrm{x} \geq 0)$ and $\mathrm{w}^{-}$ (p) for losses $(x<0)$. Because our experiment is only concerned with gains, the choice of these functions is simplified

Following Tversky and Kahneman (1991), Lattimore et al. (1992), and the estimation results they present, we assume that $v$ is a concave power function of the form

$$
v(x)=x^{c} \quad 0<c \leq 1 .
$$

This function has been used extensively in both utility function estimation (e.g., Galanter, 1962; Fishburn \& Kochenberger, 1979) and Prospect theory (Tversky \& Kahneman, 1991). (for a recent evaluation of the experimental evidence that supports concavity in the domain of gains, see Luce, 2000, Ch. 3.) Review of the literature on the shape and properties of the probability weighting function (e.g., Camerer \& Ho, 1994; Gonzalez \& Wu, 1999; Tversky \& Fox, 1995; Prelec, 1998; Tversky \& Kahneman, 1992: Wu \& Gonzalez, 1996, 1998) reveals several alternative functions. We have chosen to employ the single-parameter probability weighting function

$$
\mathrm{w}^{+}(\mathrm{p})=\exp \left[-(-\ln \mathrm{p})^{\alpha}\right], \quad 0<\alpha \leq 1,
$$

proposed by Prelec (1998). Prelec's function is the identity line when $\alpha=1$; it becomes more regressive as $\alpha$ decreases. It has a fixed point at $1 / \mathrm{e}=0.368$, which agrees with the cross-over points in Fig. 2. Like the value function $v$, it includes only a single parameter, thereby allowing for a straightforward comparison between these two independent transformations.

The value transformation applies directly to the prize values $\mathrm{g}_{\mathrm{j}}$. The probability weighting transformation applies directly to the (endogenously determined) probability of the outcome of the lottery chosen by the subject. Our purpose here is to determine whether the 
former or latter transformation (or both) can better account for the systematic deviation from equilibrium play that we reported in Fig. 2. To do so, we compute the equilibrium solution under either of these two transformations while assuming that the other transformation is kept fixed as the identity function.

Value Transformation. Assuming the same value transformation for all the $\mathrm{n}$ players, the equilibrium solution in mixed strategies consists of the probability values $\mathrm{q}_{\mathrm{j}}(\mathrm{c})$, that satisfy the $\mathrm{J}+1$ equations

$$
\frac{g_{j}{ }^{c}}{n q_{j}(c)}\left[1-\left(1-\mathrm{q}_{\mathrm{j}}(\mathrm{c})\right)^{\mathrm{n}}\right]=\mathrm{V}, \quad \mathrm{j}=1,2, \ldots, \mathrm{J}
$$

and

$$
\sum_{j=1}^{J} q_{j}(c)=1, \mathrm{q}_{\mathrm{j}}(\mathrm{c}) \geq 0
$$

Equation (3) is like Eq. (2) with $g_{j}$ replaced by $g_{j}{ }^{c}$ and $q_{j}$ by $q_{j}(c)$. The power function can be interpreted as a Prospect Theory type of value transformation or, alternatively, as a concave utility function. We wish to determine the value of $\mathrm{c}$ that minimizes the difference between the observed and predicted relative frequencies of entry summed across subjects and games. The criterion to be minimized is the root mean square deviation given by

$$
\operatorname{RMSD}(\mathrm{c})=\frac{1}{18} \sqrt{\sum_{G} \sum_{j}\left[h_{G, j}-q_{G, j}(c)\right]^{2}},
$$

where $h_{G, j}$ is the observed mean relative frequency of entry in location $\mathrm{j}$ in Game $\mathrm{G}(\mathrm{G}=1,2$, $\ldots, 6)$, and $\mathrm{q}_{\mathrm{G}, \mathrm{j}}(\mathrm{c})$ is the corresponding equilibrium probability of entry.

The best fitting value of the parameter $\mathrm{c}$ that minimizes the criterion $\operatorname{RMSD}(\mathrm{c})$ across all four groups is $\mathrm{c}=0.496$. The corresponding equilibrium expected frequencies of entry, $\mathrm{nq}_{\mathrm{j}}(\mathrm{c}=0.496)$, are presented in the third line of each panel in Table 2 . The minimum criterion value associated with $\mathrm{c}=0.496$ is $\operatorname{RMSD}(\mathrm{c}=0.496)=0.113$. This value is about one fourth of the value associated with the mixed strategy equilibrium solution under risk-neutrality, 
namely, $\operatorname{RMSD}(\mathrm{c}=1)=0.463$. The observed relative frequencies of entry are plotted against the equilibrium probabilities $\mathrm{q}_{\mathrm{j}}(\mathrm{c})$ in Fig. 3 for each group separately and across all the four groups. The figure indicates that under the assumption of a common power value function (or, alternatively, a power utility function) with parameter value $\mathrm{c}=0.496$, the mixed strategy equilibrium solution accounts for the aggregate results of each group remarkably well. To measure the goodness of fit, we regressed the observed relative frequencies summarized across all four groups on the theoretical probabilities. The percentage of variance accounted for by the solution was very high $\left(\mathrm{R}^{2}=0.906\right)$. Most importantly for our purpose, and in support of the equilibrium solution, we cannot reject the null hypothesis that the slope of the regression line $(0.994)$ is equal to unity $\left(\mathrm{t}_{17}<1\right)$ and the intercept is equal to zero.

--Insert Fig. 3 about here--

Probability Weighting Transformation. Assuming the same probability weighting transformation for all the $\mathrm{n}$ players, the equilibrium solution in mixed strategies for riskneutral players consists of the probability values $\mathrm{q}_{\mathrm{j}}(\alpha)$, that satisfy the $\mathrm{J}+1$ equations

$$
\mathrm{g}_{\mathrm{j}} \exp \left[-\left(-\ln \left(\pi_{\mathrm{j}}\right)\right)^{\alpha}\right] \quad=\mathrm{V}
$$

and

$$
\sum_{j=1}^{J} q_{j}(\alpha)=1, \mathrm{q}_{j}(\alpha) \geq 0
$$

where

$$
\pi_{\mathrm{j}}=\sum_{k=0}^{n-1}\left(\begin{array}{c}
n-1 \\
k
\end{array}\right)\left(\frac{1}{k+1}\right)\left(\mathrm{q}_{\mathrm{j}}(\alpha)\right)^{\mathrm{k}}\left[1-\mathrm{q}_{\mathrm{j}}(\alpha)\right]^{\mathrm{n}-1-\mathrm{k}}, \quad \mathrm{j}=1,2, \ldots, \mathrm{J} .
$$

As we did earlier with the value transformation, we wish to determine the value of $\alpha$ that minimizes the difference between the observed relative frequencies and the equilibrium probabilities of entry. We use the same root mean square deviation criterion, after replacing $\mathrm{q}_{\mathrm{j}}$ by $\mathrm{q}_{\mathrm{j}}(\alpha)$ and $\mathrm{c}$ by $\alpha$. 
Our results show that the probability weighting function (4) does not improve the results in any significant way, and cannot account for the deviation between the observed relative frequencies and equilibrium probabilities of entry reported above (Fig. 2). The best fitting value of $\alpha$ is 0.873 and the $\operatorname{RMDS}(\alpha=0.873)$ score is 0.395 , not much better than the reported RMSD for $\alpha=1(0.463)$. We conclude that the aggregate results can be accounted for by the mixed strategy equilibrium solution under the assumption that all the $\mathrm{n}$ players share the same attitude to risk expressed by a concave power utility function with the same parameter value.

Joint Probabilities of Entry Location Choice.

We turn next to test a major implication of mixed strategy play. In doing so, we assume that the mixed strategy equilibrium solution for risk-averse $(\mathrm{c}=0.496)$ players holds, and employ the equilibrium expected number of entries (and the corresponding probabilities) that are displayed in the third row of each panel of Table 2. Under the null hypothesis of mixed strategy equilibrium play, the 72 rounds of play of each subject should be considered as independent. Consequently, it is possible to compute the joint probabilities of choice of entry location $\mathrm{j}$ on iteration $\mathrm{t}$ of game $\mathrm{G}$ and choice of entry location $\mathrm{j}^{\prime}\left(\mathrm{j}, \mathrm{j}^{\prime}=1,2,3\right)$ on iteration $\mathrm{t}+1$ of the same game. ${ }^{6}$ These joint probabilities are time invariant, and should apply to all 11 pairs of successive iterations (excluding the first time each game was presented). Table 3 (right-hand panel) presents the expected $3 \times 3$ joint probabilities, one for each game. When multiplied by $n$, the marginal probabilities are the expected frequencies of entry presented in Table 2 (third row for risk-averse players). Each probability (shaded) to the right of the marginal probabilities is the sum of the three entries in the minor diagonal of the transition matrix. Therefore, this number is simply the probability of staying on the same location that was chosen in the previous iteration of the same game G. Table 3 shows that under mixed strategy equilibrium play the probabilities of staying on vary across the six 
games from 0.337 in Game 1 to 0.469 in Game 6, and that they slowly increase in the range of the prizes $\Delta$.

\section{--Insert Table 3 about here--}

We computed the corresponding observed joint relative frequencies of choice of entry location in successive iterations of the same game across all the subjects in the four groups (six games by 11 iterations, excluding the first presentation of each game on rounds 1 through 6). This computation was conducted for each game separately. The observed joint relative frequencies are presented in the left-hand panel of Table 3. The observed relative frequencies of staying on the same location as in the previous iteration of the game are shown to the right of the marginal relative frequencies of entry.

Although the observed marginal relative frequencies of entry are accounted for quite well by the expected marginal equilibrium probabilities (Fig. 3), the observed joint relative frequencies of staying on the same location exceed the corresponding theoretical values in each of the six games. Thus, although the subjects did not always choose the same location on successive iterations of the same game G, they tended to choose the same location more often than predicted (i.e., "inertia" effect). These results reject the mixed strategy equilibrium solution (allowing for common risk-aversion) as an explanatory concept.

This tendency of staying on the same location might be due to some or all of the subjects. Turning from the aggregate to individual data, we computed for each subject the number of times, out of 11 , that he or she chose the same location on successive iterations of the same game G. We then added up these six frequencies to obtain for each subject the total frequency of staying on, a number between 0 and 66 . The actual individual frequencies of staying on ranged between 26 and 66 with a mean of 39 . Under mixed strategy equilibrium play (for risk-averse players), the expected value and standard deviation of the number of staying on decisions are 27.18 and 4.11 , respectively. The null hypothesis that the observed 
number of staying on decisions is not different from the predicted value could not be rejected for 32 of the 72 players (44.4\%). The remaining players stayed on the same location significantly more often than predicted $(\mathrm{p}<0.01)$. With one exception, all the players occasionally changed the location of entry presumably in an attempt to increase their expected payoffs. However, more than half of them did not change their choice of location as often as predicted by the mixed strategy equilibrium solution.

\section{Effects of Under- and Over-entry.}

We may turn the issue and ask why, in the first place, did the players change the location of their entry from one iteration of game $\mathrm{G}$ to another? One possible reason is that players are mixing their strategies and choosing a location in an independent and random fashion across iterations (even if the actual choice probabilities are different from the expected probabilities based on risk-neutrality or risk-aversion assumptions). Yet another hypothesis, that allows for dependencies between iterations, is that players attempted to increase their expected payoffs by exploiting the deviations between the observed and what they considered to be the "appropriate" level of entry in each location of every game.

To test the latter hypothesis, we proceeded with the following analysis that focuses on the player's decision to either stay on the same location or switch to another location, conditional on the outcome of her previous decision. Note that for each game $G$, the ratio $r_{j}=$ $\mathrm{g}_{\mathrm{j}} /\left(\mathrm{g}_{1}+\mathrm{g}_{2}+\mathrm{g}_{3}\right), \mathrm{j}=1,2,3$, may be interpreted as the relative attraction of prize (location) $\mathrm{j}$. Therefore, $\mathrm{nr}_{\mathrm{j}}$ may be interpreted by the player as the expected number of entrants in location $\mathrm{j}$. Because of our choice of the game parameters (Table 1), $\mathrm{nr}_{\mathrm{j}}$ is also the pure strategy number of entrants in location $\mathrm{j}$. We assume that players used $\mathrm{nr}_{\mathrm{j}}$ as a benchmark for determining whether too many or too few players had decided to enter each of the three locations. In particular, for each player $\mathrm{i}$, if she entered location $\mathrm{j}$ on iteration $\mathrm{t}$, we classified the outcome for this location as "over-entry ${ }^{7}$ " if $n_{j}(t) \geq n r_{j}$ or "under-entry" if $n_{j}(t)<n r_{j}$, where 
$\mathrm{n}_{\mathrm{j}}(\mathrm{t})$ is the number of entrants in location $\mathrm{j}$ on iteration $\mathrm{t}$. We also classified player i's decision on the next iteration of the same game $\mathrm{G}$ as "staying on" if she entered the same location $\mathrm{j}$, "better switching" if she entered some other location $j^{\prime}$, where $j^{\prime}\left(j^{\prime} \neq j\right)$ is the more attractive of the two other locations, and "worse switching" if she entered some other location $\mathrm{j}$ ", where $\mathrm{j}$ " is the less attractive of the two other locations. The attractiveness of each of the other two locations is computed as the magnitude of their over- or under-entry on trial t. For example, supposing that subject $i$ entered location 1 of Game 3 (for which $g=(18,10,8)$ ) and that the number of entrants in locations 1,2, and 3 was 12, 3, and 3, respectively. The expected number of entries for this game is 9,5 , and 4, respectively. Consequently, in this case, location 1 is over-entered $(12>9)$ and locations 2 and 3 are under-entered $(3<5$ and $3<4)$. Of the latter two, location 2 is more attractive since the magnitude of under-entry $(5-3=2)$ is higher in location 2 than in location $3(4-3=1)$. In the same example, if the number of entrants into locations 1,2 , and 3 is 8,7 , and 5, respectively, this is a case of under-entry in location $1(8<9)$. Of locations 2 and 3 , location 3 is the more attractive because it is less over-entered (1 vs. 2$)^{8}$.

For each game separately and across all players, we computed six conditional probabilities. The first, $\mathrm{p}$ (stay | over), is the conditional probability of staying on the same location $\mathrm{j}$ as in the previous iteration of the same game $\mathrm{G}$, given that location $\mathrm{j}$ was oversubscribed ("over-entry"). The second, $\mathrm{p}$ (stay $\mid$ under), is defined similarly, given that location j was under-subscribed ("under-entry"). The third conditional probability, p(better switch $\mid$ over), is the probability of switching from location $\mathrm{j}$ to the more attractive location $\mathrm{j}$ ', given that location $\mathrm{j}$ was over-subscribed, and the fourth, $\mathrm{p}$ (better switch $\mid$ under), is defined similarly, given that location $\mathrm{j}$ was under-subscribed. The two remaining conditional probabilities, namely, $\mathrm{p}$ (worse switch $\mid$ over) and $\mathrm{p}$ (worse switch $\mid$ under) were computed in a 
similar way. Table 4 presents the six conditional probabilities (computed across all the players) separately for each game.

--Insert Table 4 about here--

A direct implication of virtually any adaptive learning model is that a player would be more likely to stay on location $\mathrm{j}$ on iteration $\mathrm{t}+1$ than switch to another location, if location $\mathrm{j}$ was under-subscribed on iteration t. This implication is derived by most theories of reinforcement learning (e.g., Roth \& Erev, 1995), belief learning (e.g., Fudenberg \& Levine, 1998), direction learning (Selten \& Buchta, 1999), and hybrid models like EWA (Camerer \& Ho, 1999) that combine reinforcement and belief learning. Players will be more likely to switch if location $\mathrm{j}$ was over-subscribed on iteration $\mathrm{t}^{9}$. Further, we also expect that given a decision to switch, the more attractive option (vis-à-vis the outcome of the previous iteration) will be chosen. The patterns of the results in Table 4 clearly contradict the above reasoning. First, in Games 1 to 4 players are more likely to stay at the same location after over-entry compared to under-entry. The reverse (and expected) trend is only found in Games 5 and 6. Second, given a decision to switch after over-entry, in three games (Games 1 - 3) it was toward the less attractive location, and in the other 3 games (Games 4 - 6) toward the more attractive location. The same decisions after under-entry are even more puzzling when in five out of six games (except Game 4) the switching was made toward the less attractive alternative.

We interpret these results as evidence for a kind of strategic thinking on the part of some of the players in which the next move of the remaining players is anticipated. It is as if the subject is reasoning as follows: "Because the outcome resulted in under-subscription, the tendency of the other players to enter the same location on the next time the same game is played will probably increase. As this will result in over-entry, it is therefore better for me to switch." And in the case of over-entry, it is as if the subject is reasoning as follows: "Because 
the outcome resulted in over-entry, most entrants will tend to switch to the better alternative, which consequently may become over-subscribed. Therefore, it is better for me either to stay on the same location or switch to the worse of the two locations." This interpretation is consistent with formal models that incorporate some kind of "anticipatory learning" (e.g., Ho, Camerer, \& Weigelt, 1998). It cannot be tested without first collecting additional data (e.g., by using verbal protocols or administrating post-experimental questionnaires) which bear directly on the players' cognitive processes.

\section{Generalization to Uncertain Group Size}

A major limitation of the CCP game as a model of choice between lotteries is the assumption that the values of the prizes and the number of group members are commonly known. In reality (e.g., choice of which state lottery to enter) the values of the prizes are typically private knowledge and it is only reasonable to assume that the distribution of the number of agents, rather than the exact number of agents, is commonly known. To relax the latter limitation, we generalize below the CCP game to the case where only the distribution of the number of agents is commonly known. We show that if the expected value of this distribution is relatively large, the effect of uncertainty is negligible.

Assume that the group size has a commonly known distribution in which the random variable $n_{h}$ takes on the values $n_{1}, n_{2}, \ldots, n_{H}$ with respective probabilities $p_{1}, p_{2}, \ldots, p_{H}$. Then, the equilibrium solution in mixed strategies for risk-neutral players consists of the probabilities $\mathrm{q}_{1}, \mathrm{q}_{2}, \ldots, \mathrm{q}_{\mathrm{J}}$, which satisfy the following $\mathrm{J}+1$ equations in $\mathrm{J}+1$ unknowns $\left(\mathrm{q}_{1}, \mathrm{q}_{2}, \ldots, \mathrm{q}_{\mathrm{J}}, \mathrm{V}\right)$ :

$$
\begin{aligned}
& \sum_{h=1}^{H} p_{h}\left[\mathrm{~g}_{\mathrm{j}} \sum_{k=0}^{m_{j}-1}\left(\begin{array}{c}
n_{h}-1 \\
k
\end{array}\right) \mathrm{q}_{\mathrm{j}}{ }^{\mathrm{k}}\left(1-\mathrm{q}_{\mathrm{j}}\right)^{n_{h}-1-\mathrm{k}}\right. \\
& \left.+\mathrm{g}_{\mathrm{j}} \sum_{k=m_{j}}^{n_{h}-1}\left(\begin{array}{c}
n_{h}-1 \\
k
\end{array}\right)\left(\frac{m_{j}}{k+1}\right) \mathrm{q}_{\mathrm{j}}{ }^{\mathrm{k}}\left(1-\mathrm{q}_{\mathrm{j}}\right)^{n_{h}-1-\mathrm{k}}\right]=\mathrm{V},
\end{aligned}
$$


and

$$
\mathrm{q}_{1}+\mathrm{q}_{2}+\ldots+\mathrm{q}_{\mathrm{J}}=1, \quad \mathrm{q}_{\mathrm{j}} \geq 0, \mathrm{j}=1,2, \ldots, \mathrm{J} .
$$

In the special case examined in the present study, where each location includes a single prize only, these equations simplify to

$$
\sum_{h=1}^{H} p_{h}\left[\mathrm{~g}_{\mathrm{j}} \sum_{k=0}^{m_{j}-1}\left(\begin{array}{c}
n_{h}-1 \\
k
\end{array}\right)\left(\frac{1}{k+1}\right) \mathrm{q}_{\mathrm{j}}^{\mathrm{k}}\left(1-\mathrm{q}_{\mathrm{j}}\right)^{n_{h}-1-\mathrm{k}}\right]=\mathrm{V}
$$

and

$$
\mathrm{q}_{1}+\mathrm{q}_{2}+\ldots+\mathrm{q}_{\mathrm{J}}=1, \quad \mathrm{q}_{\mathrm{j}} \geq 0, \mathrm{j}=1,2, \ldots, \mathrm{J} .
$$

Further simplifying this expression as in Section 2, we obtain the system of equalities

$$
\sum_{h=1}^{H} p_{h}\left(\frac{g_{j}}{n q_{j}}\left[1-\left(1-\mathrm{q}_{\mathrm{j}}\right)^{n_{h}}\right]\right)=\mathrm{V}
$$

and

$$
q_{1}+q_{2}+\ldots+q_{J}=1, q_{j} \geq 0, j=1,2, \ldots, J .
$$

We assumed a (discrete) uniform distribution of number of players with $\mathrm{p}_{1}=\mathrm{p}_{2}=\ldots$ $=\mathrm{p}_{\mathrm{H}}$ and expected value $\mu_{\mathrm{n}}=18$. We then increased systematically the range of the distribution (e.g., $\mathrm{n} \pm 1=[17,18,19], \mathrm{n} \pm 2=[16,17,18,19,20]$, up to $\mathrm{n} \pm 5$ ), and solved the system of equations (5) for each of these five cases separately to investigate the effect of the range of the distribution of $n_{h}$ on the mixed strategy equilibrium solution. For each of our six games (Table 1), the changes in the equilibrium probability $q_{j}$ for the cases $n \pm 1$ through $\mathrm{n} \pm 5$ were in the third decimal point. In Game 6 , which provides the most extreme case, the equilibrium solution for $\mathrm{n} \pm 5$ was $\left(\mathrm{q}_{1}, \mathrm{q}_{2}, \mathrm{q}_{3}\right)=(0.896,0.099,0.005)$. In contrast (Table 1$)$, the equilibrium solution for the case when $\mathrm{n}=18$ with certainty is $\left(\mathrm{q}_{1}, \mathrm{q}_{2}, \mathrm{q}_{3}\right)=(0.891,0.101$, 0.008). In all other cases, the discrepancy between the uncertain and certain cases was much smaller. These results show that the effect of uncertainty about group size decreases as 1) the expected value $\mu_{\mathrm{n}}$ increases, and 2) the magnitude of uncertainty decreases. They suggest that 
when $\mu_{\mathrm{n}}$ is relatively large, as in our experiment, the effects of uncertainty about group size are negligible.

\section{Discussion}

Our study was designed to investigate the lottery mechanism for distributing limited supply of some indivisible good when demand exceeds supply. We conducted this investigation experimentally in a conflict situation that allows for both strategic and outcome uncertainties. The CCP game was introduced to model interactive decision situations in which agents have to choose one of several independent lotteries. The standard solution concept for this class of interactive decision making situations is the Nash equilibrium, namely, a profile of $\mathrm{n}$ independent decisions, pure or mixed, from which no player wishes to deviate unilaterally. On the aggregate level, our results support the solution concept remarkably well under the assumption of common risk-aversion in the domain of gains. However, we find no evidence for mixed strategy play on the individual level. Nor do we find evidence for learning trends across blocks of trials. We comment on these findings below. Aggregate Results. Our analysis shows no evidence that the systematic discrepancy between the observed relative frequencies of choice of entry location and the predicted probabilities under the assumption of risk-neutrality can be accounted for by a probability weighting transformation of the kind proposed by Prospect Theory. We have been quite successful in explaining this discrepancy by assuming common risk-aversion. Our results (Fig. 3) show that for each of the four groups this discrepancy largely disappears once we assume a commonly shared risk attitude captured by a concave power function with a parameter value $c=0.496$. Because our study is only concerned with the domain of gains, as all the prizes in our six games were positive, the alternative interpretations of this power function as a Prospect Theory value function or a classical utility function coincide. The two 
interpretations could be compared to each other if we introduced more complicated lotteries that allow for both positive and negative prizes.

We are uneasy about specifying a Prospect Theory type value (or utility function) parameter that has the effect of pushing the equilibrium predictions in the direction of the observed data. As Friedman noted, “arbitrary special utility effects could 'explain' virtually any sort of data" (1982, p. 1376). We find it reassuring that the value function that we used has received considerable support in the extensive literature on Prospect Theory that focuses on individual choice behavior. Our risk-aversion parameter estimate is slightly lower than the estimates reported by Cox and Oaxaca (1996) and Tversky and Kahneman (1992) in completely different contexts. It is very close to the risk aversion coefficient reported by Harrison (1990) in the 4-person experiment of Cox, Robertson, and Smith (1982) that he considered. And it is almost identical to the estimated risk aversion coefficient $(\mathrm{c}=0.52)$ reported in a recent experiment on private-value auctions conducted by Goeree, Holt, and Palfrey (1999). Goeree et al. observed overbidding relative to the risk-neutral Nash equilibrium prediction in their experiments. Assuming that their subjects exhibit constant risk aversion, with estimated (pooled) parameter value of $\mathrm{c}=0.52$, they succeeded in tracking the conditional bid averages quite successfully as well as reproducing the entire frequency distributions of bidding decisions.

Individual Results. We go beyond Goeree et al. in testing the equilibrium model on the individual level. Our results show that although the equilibrium solution organizes the aggregate results quite well, it does not account for the individual behavior. With communication not allowed and group size being quite large, it was not possible for our players to achieve coordination through pure strategy equilibrium play. The patterns of joint relative frequencies of choice presented in Table 3 and conditional probabilities of staying on the same location or switching to another location shown in Table 4 are largely inconsistent 
with mixed strategy play. Rather, our results show marked individual differences. They suggest that the orderly aggregate behavior is in fact a product of a variety of individual decision rules. Some of our players mix their choices, not unlike the predictions of the equilibrium solution, whereas others strive to achieve coordination by attempting to increase their expected payoff across trials through some sort of strategic play based on anticipation of the other players' future moves.

This strategic play often takes the form of "best reply to anticipated best reply by the other players." It resembles similar conceptualizations of a hierarchy of levels of strategic thinking in a model proposed by Stahl and Wilson (1995). Our experimental design is not suited for testing the hypothesis of a negative correlation between player i's tendency to use a particular decision rule and the tendency of the other group members to use the same rule. An experimental design in which games are presented in a blocked design, similar to the one used in the study of tacit coordination in market entry games by Erev and Rapoport (1998), rather than a randomized design, as used in the present study, is more suitable.

Learning. We observe no major trends across blocks in the level of coordination achieved by our subjects (Fig. 1). This result is puzzling because previous experimental studies of tacit coordination in large group market entry games (e.g., Erev \& Rapoport, 1998; Rapoport, Seale, \& Parco, in press; Rapoport, Seale, \& Winter, 2000) reported steady improvement in coordination on the aggregate level for the first fifty trials or so. We hypothesize that the difference between "flat" and "non-flat" learning curves is mainly due to two major differences between these two classes of studies. First, whereas the previous market entry game experiments included only strategic uncertainty, the present study included both strategic and outcome uncertainty. Second, the market entry game experiments provided the subject with an option to stay out of the market, whereas the present study did not provide this option. These differences might have led the subjects to achieve tacit coordination- 
remarkable in both cases - through different adjustment processes, namely, slow emergence of cutoff decision rules in the market entry games vs. some combination of randomization with best reply to anticipated group behavior in the present study. Additional studies of coordination using other tasks that manipulate both sources of uncertainty and the presence or absence of an outside option are needed to test this hypothesis. 


\section{References}

Camerer, C. F. \& Ho, T.-H. (1994). Violations of the betweenness axiom and nonlinearity in probability. Journal of Risk and Uncertainty, $\underline{8}, 167-196$.

Camerer, C. \& Ho, T.-H. (1999). Experience-weighted attraction learning in normal form games. Econometrica, $\underline{67}, 827-874$.

Cox, J. C. \& Oaxaca, R. L. (1996). Is bidding behavior consistent with bidding theory for private value auctions? In M. Issac (Ed.), Research in Experimental Economics, Vol. 6, Greenwich, Conn.: JAI Press, pp. $131-148$.

Cox, J. C., Robertson, B., \& Smith V. L. (1982). Theory and behavior of single price auctions. In V. L. Smith (ED.), Research in Experimental Economics, Vol. 2, Greenwich, Conn.: JAI Press, pp. $1-43$.

Erev. I. \& Rapoport, A. (1998). Coordination, "magic", and reinforcement learning in a market entry game. Games and Economic Behavior, 23, 146 - 175.

Fishburn, P. \& Kochenberger, G. A. (1979). Two-piece von Neumann-Morgenstern utility functions. Decision Sciences, $\underline{10}, 503-518$.

Friedman, D. (1992). Theory and misbehavior of first-price auctions: Comment. American Economic Review, $\underline{82}, 1374-1378$.

Fudenberg, D. \& Levine, D. K. (1998). The Theory of learning in Games. Cambridge, MA: The MIT Press.

Galanter, E. (1962). The direct measurement of utility and subjective probability. American Journal of Psychology, 75, 208 - 220.

Goeree, J. K., Holt, C. A., \& Palfrey, T. R. (1999). Quantal response equilibrium and overbidding in private-value auctions. California Institute of technology, Division of Humanities and Social Sciences, Pasadena, CA, Unpublished manuscript. 
Gonzalez, R. \& Wu, G. (1999). On the form of the probability weighting function. Cognitive Psychology, $\underline{38}, 129-166$.

Harrison, G. W. (1990). Theory and misbehavior of first-price auctions. American Economic Review, $\underline{79}, 749-762$.

Ho, T.-H., Camerer, C., \& Weigelt, K. (1998). Iterated dominance and iterated bestresponse in $p$-beauty contests. American Economic Review, $\underline{88}, 947$ - 969.

Kahneman, D., Knetsch, J. L., \& R.H. Thaler (1986). Fairness and the assumptions of economics. Journal of Business, $\underline{59}$, 285-300.

Kahneman D. \& Tversky, A. (1979). Prospect theory: An analysis of decision under risk. Econometrica, 47, 263 - 291.

Lattimore, P. M., Baker, J. R., \& Witte, A. D. (1992). The influence of probability on risky choice. Journal of Economic Behavior and Organization, 17, 377 - 400.

Luce, R. D. (2000). Utility of Gains and Losses: Measurement-Theoretical and Experimental Approaches. Mahwah, NJ: Erlbaum.

Prelec, D. (1998). The probability weighting function. Econometrica, $\underline{66}, 497$ - 527.

Preston, M. G. \& Baratta, P. (1948). An experimental study of the auction value of an uncertain outcome. American Journal of Psychology, 61, 183 - 193.

Rapoport, A. Seale, D. A., \& Parco, J. A. (in press). Coordination in the aggregate without common knowledge or outcome information. In R. Zwick \& A. Rapoport (Eds.) Experimental Business Research. New York: Kluwer.

Rapoport, A. Seale, D. A., \& Winter, E. (2000). An experimental study of coordination and learning in iterated two-market entry games. Economic Theory, $\underline{19}, 163-$ 184. 
Roth. A. E. \& Erev, I. (1995). Learning in extensive-form games: Experimental data and simple dynamic models in the intermediate term. Games and Economic Behavior, $\underline{8}$, $164-212$.

Selten, R. \& Buchta, J. (1999). Experimental sealed bid first auctions with directly observed bid functions. In D. V. Budescu, I. Erev, \& R. Zwick (Eds.), Games and Human Behavior: Essays in Honor of Amnon Rapoport. Mahwah, NJ: Erlbaum.

Stahl, D. O \& Wilson, P. W. (1995). On players' models of other players: Theory and experimental evidence. Games and Economic Behavior, 10, 218 - 254.

Tversky, A. \& Fox, C. R. (1995). Weighing risk and uncertainty. Psychological $\underline{\text { Review, }}$ 102, $269-283$.

Tversky, A. \& Kahneman, D. (1991). Loss aversion in riskless choice: A referencedependent model. Quarterly Journal of Economics, 107, 1039 - 1061.

Tversky, A. \& Kahneman, D. (1992). Advances in prospect theory: Cumulative representation of uncertainty. Journal of Risk and Uncertainty, $\underline{5}, 297$ - 323.

Tversky, A. \& Wakker, P. (1995). Risk attitudes and decision weights. Econometrica, $\underline{63}, 1255-1280$.

Wu, G. \& Gonzalez, R. (1996). Curvature of the probability weighting function. Management Science, $\underline{42}, 1676-1690$.

Wu, G. \& Gonzalez, R. (1998). Common consequence conditions in decision making under risk. Journal of Risk and Uncertainty, 16, 115 - 139.

Young, H. P. (1994). Equity. Princeton: Princeton University press. 
APPENDIX

Instruction (first twelve screens)

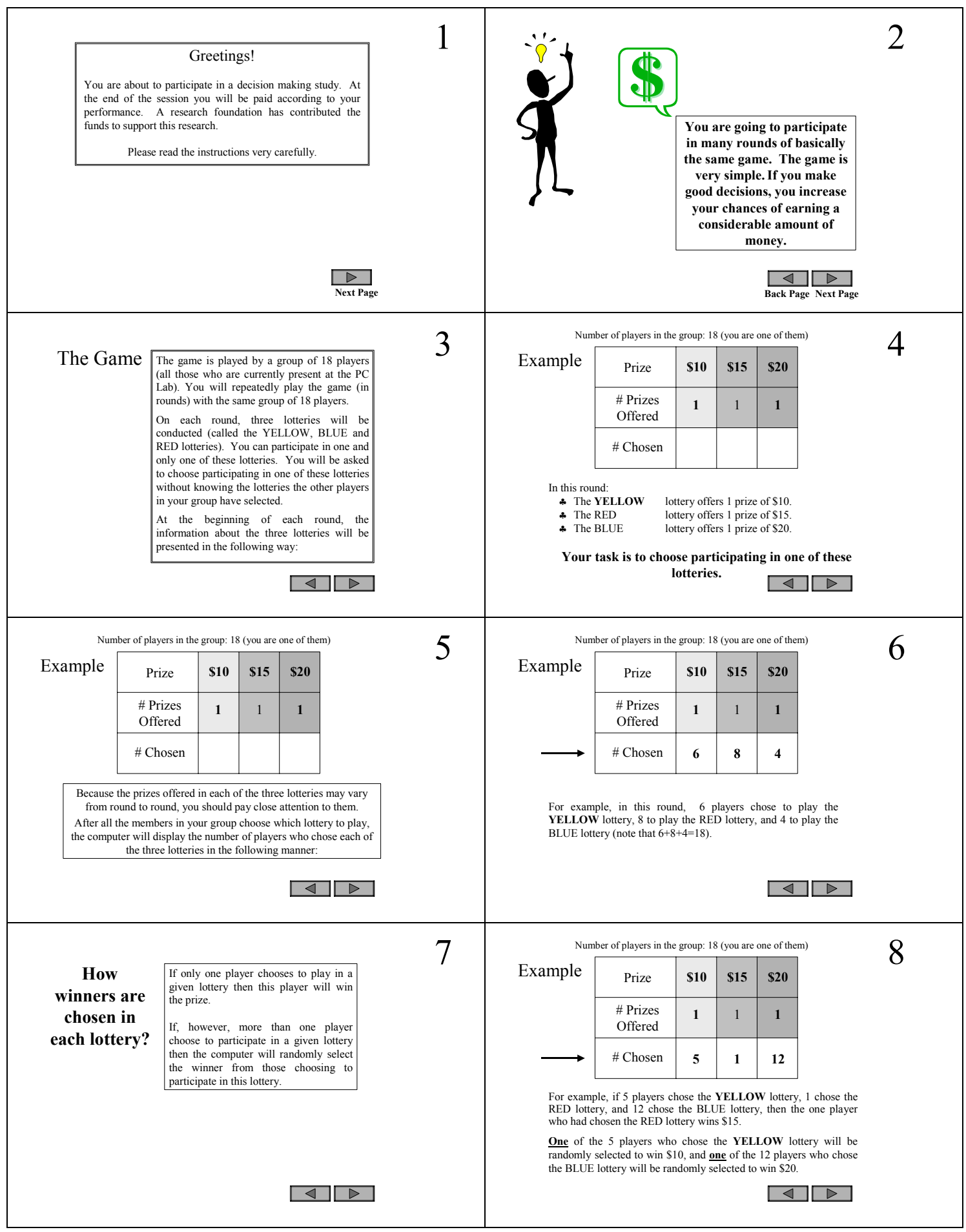




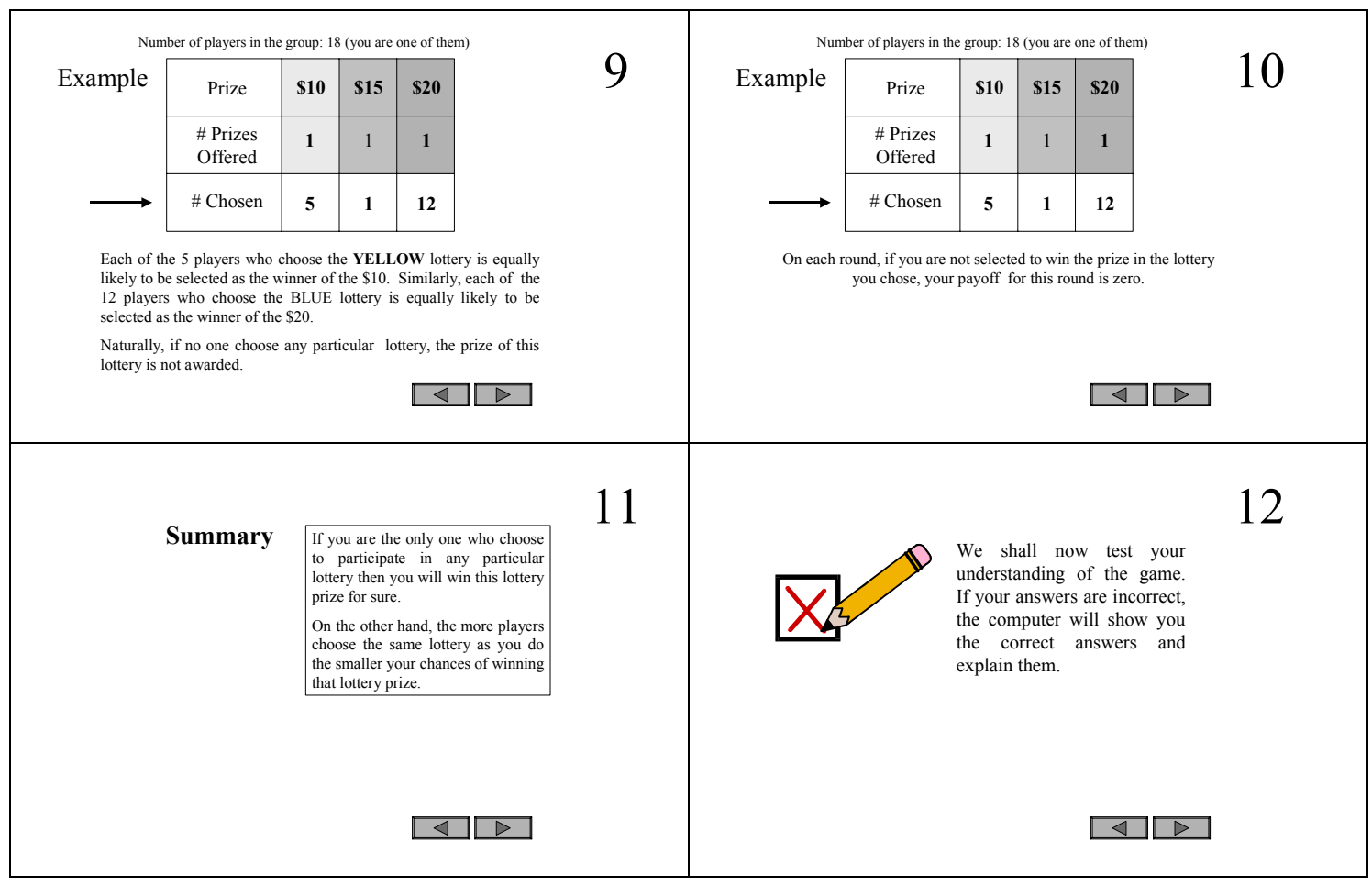


Table 1

Parameter Values and Equilibrium Solutions for the Six Games

\begin{tabular}{|c|c|c|c|c|c|c|c|c|c|c|c|c|c|}
\hline \multirow[b]{2}{*}{ Game G } & \multicolumn{4}{|c|}{ Prize Values } & \multicolumn{3}{|c|}{ No. of Prizes } & \multicolumn{3}{|c|}{$\begin{array}{l}\text { Pure Strategy } \\
\text { Equilibrium }\end{array}$} & \multicolumn{3}{|c|}{$\begin{array}{l}\text { Mixed Strategy } \\
\text { Equilibrium }\end{array}$} \\
\hline & $\mathrm{g}_{1}$ & $\mathrm{~g}_{2}$ & $\mathrm{~g}_{3}$ & $\Delta$ & $\mathrm{m}_{1}$ & $\mathrm{~m}_{2}$ & $\mathrm{~m}_{3}$ & $\mathrm{n}_{1}{ }^{*}$ & $\mathrm{n}_{2}{ }^{*}$ & $\mathrm{n}_{3}{ }^{*}$ & $\mathrm{q}_{1}$ & $\mathrm{q}_{2}$ & $\mathrm{q}_{3}$ \\
\hline 1 & 14 & 12 & 10 & 4 & 1 & 1 & 1 & 7 & 6 & 5 & .389 & .334 & .277 \\
\hline 2 & 16 & 14 & 6 & 10 & 1 & 1 & 1 & 8 & 7 & 3 & .447 & .392 & .161 \\
\hline 3 & 18 & 10 & 8 & 10 & 1 & 1 & 1 & 9 & 5 & 4 & .502 & .278 & .220 \\
\hline 4 & 20 & 14 & 2 & 18 & 1 & 1 & 1 & 10 & 7 & 1 & .585 & .409 & .006 \\
\hline 5 & 24 & 8 & 4 & 20 & 1 & 1 & 1 & 12 & 4 & 2 & .681 & .225 & .094 \\
\hline 6 & 30 & 4 & 2 & 28 & 1 & 1 & 1 & 15 & 2 & 1 & .891 & .101 & .008 \\
\hline
\end{tabular}


Table 2

Means (and STD) of Observed and Expected Mixed Strategy Equilibrium Number of Entries

\begin{tabular}{|c|c|c|c|c|c|c|c|c|}
\hline \multirow[b]{2}{*}{ Game } & & & \multicolumn{2}{|c|}{$\mathrm{j}=1$} & \multicolumn{2}{|c|}{$j=2$} & \multicolumn{2}{|c|}{$j=3$} \\
\hline & & & Mean & SD & Mean & SD & Mean & $\mathrm{SD}$ \\
\hline \multirow[t]{3}{*}{1} & Observed & & 7.312 & 2.031 & 5.417 & 1.916 & 5.271 & 2.189 \\
\hline & Expected & Risk-neutral & 7.002 & 2.068 & 6.012 & 2.001 & 4.986 & 1.899 \\
\hline & Expected & Risk-averse* & 6.831 & 2.059 & 5.499 & 1.954 & 5.670 & 1.971 \\
\hline \multirow[t]{3}{*}{2} & Observed & & 8.000 & 1.888 & 5.333 & 1.840 & 4.667 & 2.134 \\
\hline & Expected & Risk-neutral & 8.046 & 2.109 & 7.056 & 2.071 & 2.898 & 1.559 \\
\hline & Expected & Risk-averse & 6.995 & 2.068 & 6.152 & 2.012 & 4.853 & 1.883 \\
\hline \multirow[t]{3}{*}{3} & Observed & & 7.542 & 1.798 & 5.917 & 1.991 & 4.542 & 1.723 \\
\hline & Expected & Risk-neutral & 9.036 & 2.121 & 5.004 & 1.901 & 3.960 & 1.757 \\
\hline & Expected & Risk-averse & 7.671 & 2.098 & 5.347 & 1.939 & 4.982 & 1.898 \\
\hline \multirow[t]{3}{*}{4} & Observed & & 9.125 & 2.060 & 5.875 & 2.077 & 3.000 & 1.545 \\
\hline & Expected & Risk-neutral & 10.530 & 2.090 & 7.362 & 2.086 & 0.108 & 0.328 \\
\hline & Expected & Risk-averse & 8.376 & 2.116 & 6.640 & 2.047 & 2.984 & 1.578 \\
\hline \multirow[t]{3}{*}{5} & Observed & & 9.000 & 1.534 & 5.250 & 1.610 & 3.750 & 1.536 \\
\hline & Expected & Risk-neutral & 12.258 & 1.977 & 4.050 & 1.772 & 1.692 & 1.238 \\
\hline & Expected & Risk-averse & 9.393 & 2.119 & 5.238 & 1.927 & 3.369 & 1.655 \\
\hline \multirow[t]{3}{*}{6} & Observed & & 11.563 & 1.717 & 3.583 & 1.738 & 2.854 & 1.416 \\
\hline & Expected & Risk-neutral & 16.038 & 1.322 & 1.818 & 1.278 & 0.144 & 0.378 \\
\hline & Expected & Risk-averse & 11.393 & 2.045 & 3.775 & 1.727 & 2.832 & 1.545 \\
\hline
\end{tabular}

* Assuming that $v(x)=x^{0.496}$ 
Table 3

Observed and Predicted Probabilities of Selecting locations on Successive Iterations of the Same Game

\begin{tabular}{|c|c|c|c|c|c|c|c|c|c|}
\hline \multirow[b]{2}{*}{ Game } & & \multicolumn{4}{|c|}{ Observed } & \multicolumn{4}{|c|}{ Predicted* (Mixed Eq.) } \\
\hline & & $j=1$ & $\mathrm{j}=2$ & $j=3$ & & $\mathrm{j}=1$ & $\mathrm{j}=2$ & $\mathrm{j}=3$ & \\
\hline \multirow[t]{4}{*}{1} & $\mathrm{j}=1$ & .199 & .109 & .105 & & 0.144 & 0.116 & 0.120 & \\
\hline & $\mathrm{j}=2$ & .095 & .121 & .085 & & 0.116 & 0.093 & 0.096 & \\
\hline & $j=3$ & .116 & .072 & .098 & & 0.120 & 0.096 & 0.099 & \\
\hline & Sum & .410 & .302 & .288 & .418 & 0.380 & 0.306 & 0.315 & .337 \\
\hline \multirow[t]{4}{*}{2} & $\mathrm{j}=1$ & .253 & .102 & .092 & & 0.151 & 0.133 & 0.105 & \\
\hline & $\mathrm{j}=2$ & .115 & .117 & .067 & & 0.133 & 0.117 & 0.092 & \\
\hline & $j=3$ & .081 & .067 & .106 & & 0.105 & 0.092 & 0.073 & \\
\hline & Sum & .449 & .286 & .265 & .476 & 0.389 & 0.342 & 0.270 & .341 \\
\hline \multirow[t]{4}{*}{3} & $\mathrm{j}=1$ & .230 & .110 & .078 & & 0.182 & 0.127 & 0.118 & \\
\hline & $\mathrm{j}=2$ & .116 & .130 & .083 & & 0.127 & 0.088 & 0.082 & \\
\hline & $j=3$ & .066 & .091 & .096 & & 0.118 & 0.082 & 0.077 & \\
\hline & Sum & .412 & .331 & .257 & .456 & 0.426 & 0.297 & 0.277 & .346 \\
\hline \multirow[t]{4}{*}{4} & $j=1$ & .319 & .128 & .057 & & 0.217 & 0.172 & 0.077 & \\
\hline & $j=2$ & .133 & .158 & .039 & & 0.172 & 0.136 & 0.061 & \\
\hline & $j=3$ & .053 & .038 & .076 & & 0.077 & 0.061 & 0.027 & \\
\hline & Sum & .505 & .324 & .172 & .553 & 0.465 & 0.369 & 0.166 & .380 \\
\hline \multirow[t]{4}{*}{5} & $\mathrm{j}=1$ & .326 & .122 & .062 & & 0.272 & 0.152 & 0.098 & \\
\hline & $\mathrm{j}=2$ & .109 & .102 & .071 & & 0.152 & 0.085 & 0.054 & \\
\hline & $\mathrm{j}=3$ & .061 & .071 & .077 & & 0.098 & 0.054 & 0.035 & \\
\hline & Sum & .496 & .295 & .210 & .505 & 0.522 & 0.291 & 0.187 & .392 \\
\hline \multirow[t]{4}{*}{6} & $j=1$ & .489 & .083 & .073 & & 0.401 & 0.133 & 0.100 & \\
\hline & $\mathrm{j}=2$ & .093 & .062 & .040 & & 0.133 & 0.044 & 0.033 & \\
\hline & $j=3$ & .057 & .053 & .049 & & 0.100 & 0.033 & 0.025 & \\
\hline & Sum & .640 & .198 & .162 & .600 & 0.633 & 0.210 & 0.157 & .469 \\
\hline
\end{tabular}

* These are the mixed strategy equilibrium probabilities under the assumption of a common power value (utility) function with a parameter $\mathrm{c}=0.496$. 
Table 4

Mean Conditional Probabilities of Staying on and Switching between Successive Iterations of the Same Game

\begin{tabular}{lcccccc}
\hline & \multicolumn{5}{c}{ Game } \\
& 1 & 2 & 3 & 4 & 5 & 6 \\
\cline { 2 - 7 } & 0.489 & 0.557 & 0.530 & 0.624 & 0.354 & 0.222 \\
$\mathrm{p}$ (stay $\mid$ over) & 0.170 & 0.198 & 0.205 & 0.233 & 0.396 & 0.542 \\
$\mathrm{p}$ (wotter switch $\mid$ over) & 0.341 & 0.245 & 0.265 & 0.143 & 0.250 & 0.236 \\
$\mathrm{p}$ (stay $\mid$ under) & 0.337 & 0.355 & 0.366 & 0.446 & 0.456 & 0.604 \\
$\mathrm{p}$ (better switch $\mid$ under) & 0.294 & 0.279 & 0.238 & 0.328 & 0.229 & 0.170 \\
$\mathrm{p}$ (worse switch $\mid$ under) & 0.369 & 0.366 & 0.396 & 0.226 & 0.315 & 0.226 \\
\hline
\end{tabular}




\section{Figure captions}

Figure 1 - Running Average of Deviation from Mixed Strategy Equilibrium

Figure 2 - Observed Frequencies Of Entry Vs. Risk-Neutral Mixed Strategy Equilibrium Probabilities Of Entry

Figure 3- Observed Frequencies Of Entry Vs. Risk-Averse Mixed Strategy Equilibrium Probabilities Of Entry 
Figure 1
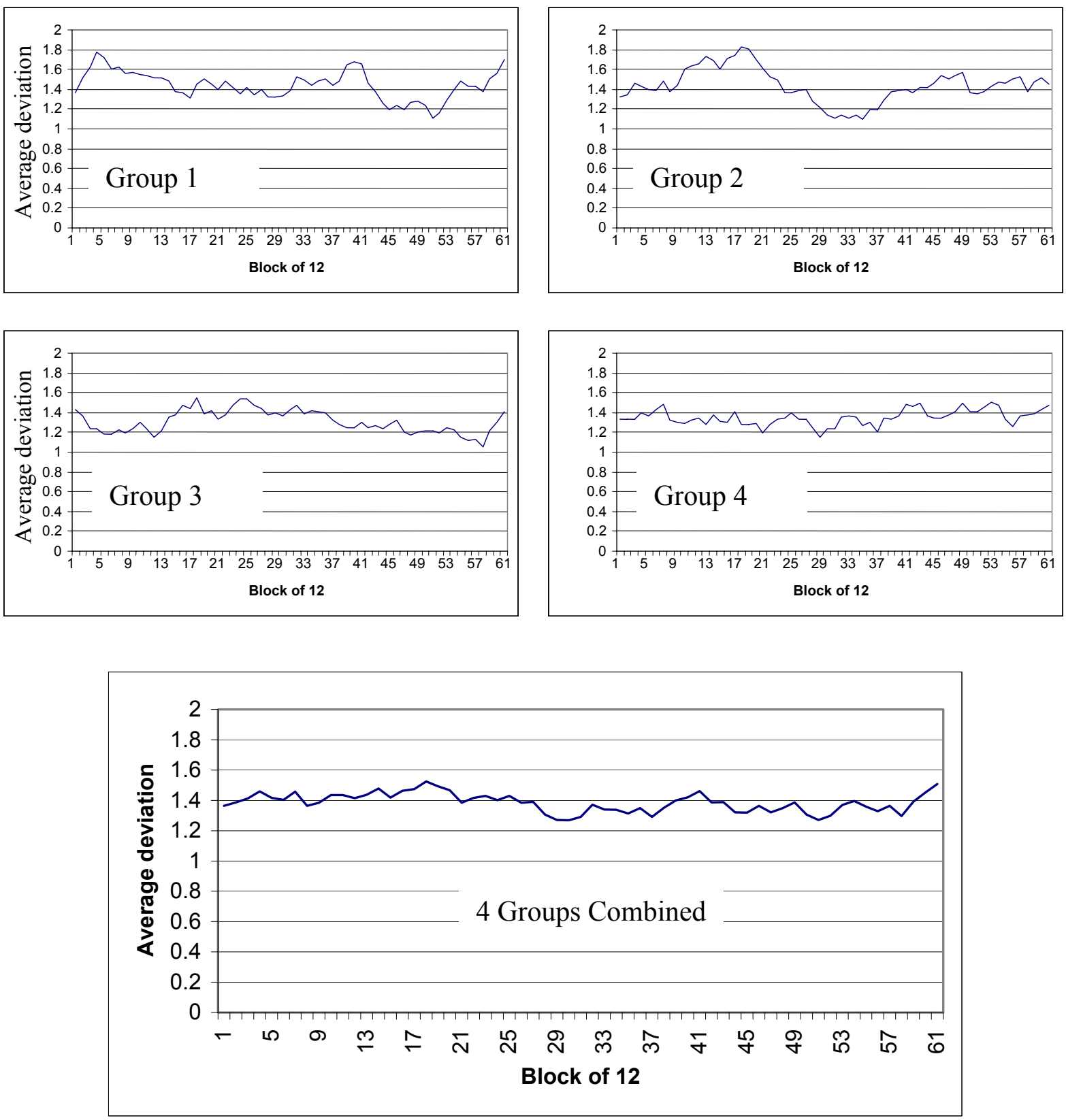
Figure 2
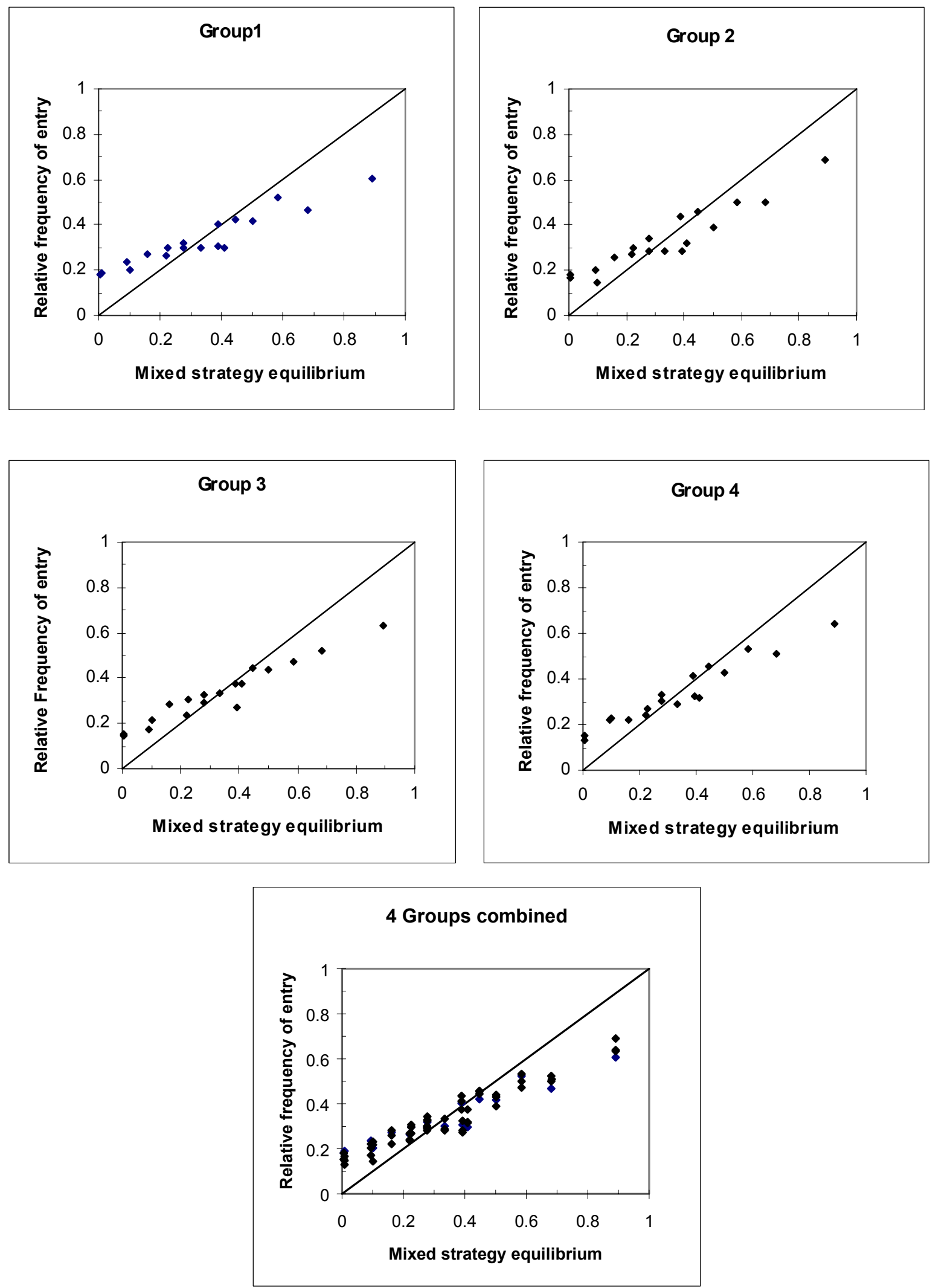
Figure 3
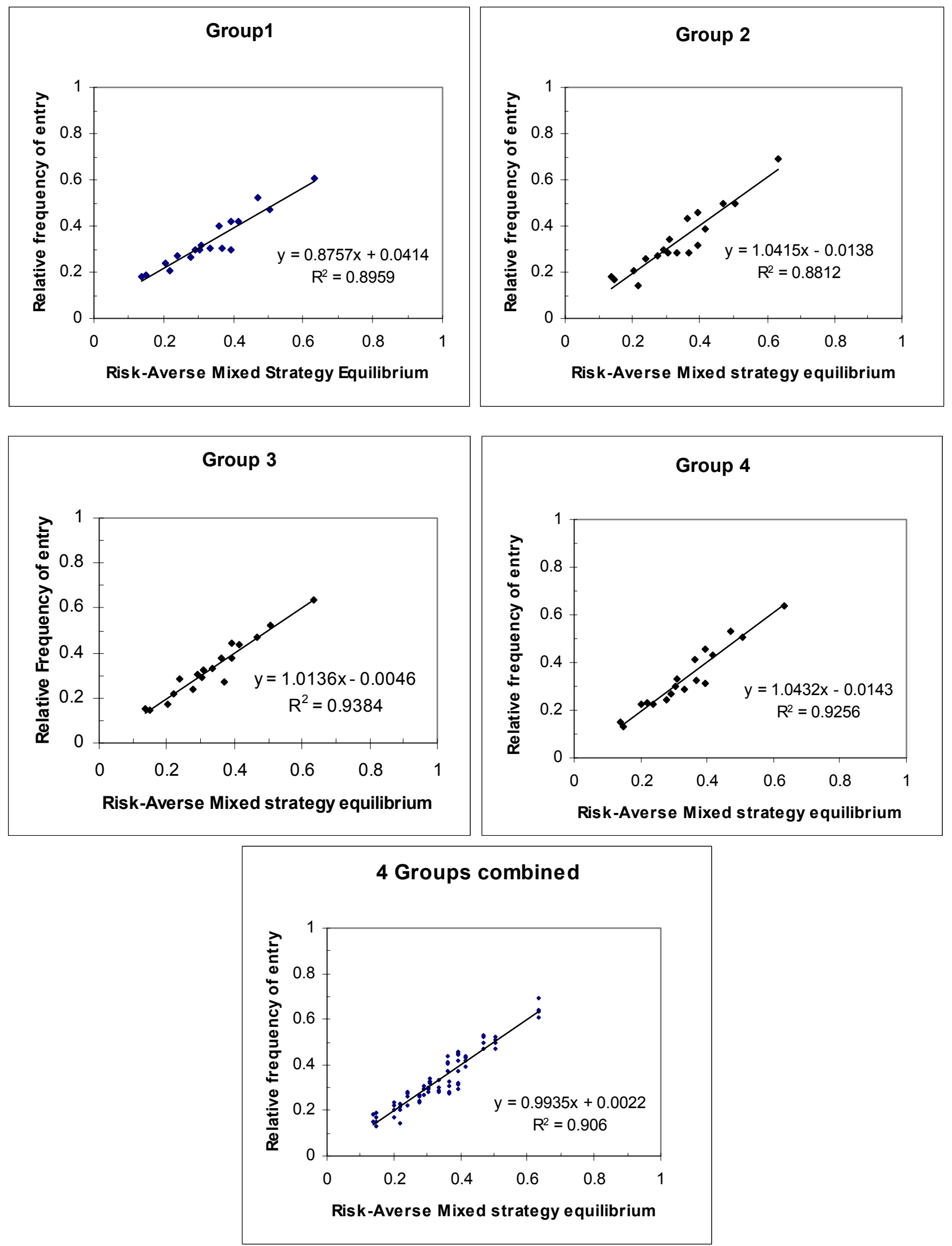


\section{Endnotes}

\footnotetext{
${ }^{1}$ See, for example, the uproar over the news (in October 1999) that Coca-Cola Co. is studying wireless technology that could allow bottlers to raise or lower soda prices by remote control at certain times - say, during hot weather. Lower prices during periods of slower sales would presumably bring in more business.

${ }^{2}$ Or a probability that is based on an objective criterion such as the number of shares paid for in an IPO.

${ }^{3}$ The amount of the cash prize was very attractive to students considering that the hourly wage for an oncampus job was about HK\$50 (US\$6.45).

${ }^{4}$ In a "browse at a kiosk (full screen)" mode.

${ }^{5}$ The full instructions in PowerPoint format are available in http://home.ust.hk/ mkzwick/papers/CCPinstructions.ppt
}

${ }^{6}$ Any two iterations of the same game $G$ are separated on the average by six rounds of play. This number changes across blocks because of the independent randomization of the six games in each block.

${ }^{7}$ The "over-entry" category includes the cases where $n_{j}(t)=n_{j}$. The results are not affected if we exclude these cases from this category.

${ }^{8}$ If two locations have the same magnitude of over- or under-entry, the one with the higher prize is considered to be the more attractive one.

${ }^{9}$ The assumption is that even if the subject actually won the prize (when the location he selected was over subscribed) he should attribute a large portion of his success to luck rather than to wise decision making. 